\title{
Teachers, Studens, Homework
}

\section{Chunli Pu}

Honghe University, Mengzi, Honghe Hani and Yi Autonomous Prefecture, Yunnan, China.

Abstract: The function of homework is to meet teaching purpose and learning goal. From teachers' and students' point of view, this thesis refers some advice on how to assign and grade students homework. It has some reference value.

Keywords:Homework; Goal; Purpose

\section{Introduction}

For students, they are required to finish homework after school. For teachers, they often assign students some homework to meet the specific goal. Thesis tries to analyze the relation of teachers, students and homework.

Concerning the purpose of homework, Van Voorhis offers the following ideas: "Practice, preparation, participation, personal development, parent-child relations,parent-teacher communications, peer interactions, policy, public, relations, punishment"(Van Voorhis, 2004, p. 207).

Teachers assign students special homework to help students review or preview the knowledge they have learned or will learn. So teachers play a vital role in the designing of homework. Van (2011) writes in his paper: "Better homework practice does not necessitate more students time, but it does require improved homework design and professional development time for teacher" (p. 242). Teachers should consider carefully the functions of it, purpose, varieties, types and the other things related to homework. Homework design incarnates a teacher's knowledge level. An excellent teacher should take the students' skills, abilities, needs, characteristics and the family into account. It's vital to consider the following aspects: take the homework as a useful teaching tool, and an effective learning method. When assigning students homework, teachers should pay more attention to the homework's purpose and goals. (Epstein \& Voorhis, 2000).

There's no consistency between teachers and grade levels. Some teachers assign piles of homework but others just assign little or no homework. Much homework does not meet the educational goals. Homework is designed too much for students. The daily routines are piled. Students have not enough time to finish their homework carefully. Some teachers assign homework to meet the parents' expectations (Brock, Lapp, Flood, Fisher, \& Han, 2007). So when teachers give students homework, they can follow the Confucius's saying. It's to go too far is as bad as to fall short. It means that to do too much of something is equally as bad as not doing enough. Some teachers assign homework only because they are required to do. Many homework assignments do not achieve the educational goals. The form of some teachers' homework is simple. Besides giving lectures to students, teachers have many things to do. They have to develop themselves all along. They have to finish their family obligation. They have to face up to all kinds of outside school things. From the view of students, they hope their teachers grade their homework immediately and return it right away and it's better with feedback.

Students have the same expectations. It's understandable and acceptable. Therefore, teachers should work hard to meet the students need. When teachers cannot fulfill students' requirement, they should consider it carefully before giving students assignments. It can't be too easy or too difficult. If it's too easy, students will think it's not worthy of

Copyright $\odot 2020$ Chunli Pu

doi: $10.18282 /$ le.v9i6.1352

This is an open-access article distributed under the terms of the Creative Commons Attribution Non-Commercial License

(http://creativecommons.org/licenses/by-nc/4.0/), which permits unrestricted non-commercial use, distribution, and reproduction in any medium, provided the original work is properly cited. 
the effort and lack of challenge. And if it's too difficult, most students will feel frustrated. They will lose their interest to do. They may refuse to keep the teachers' subject. To most Chinese students, writing composition is one of the biggest challenges. They cannot shift the book knowledge into their own knowledge. Therefore, there must be many mistakes in the writing homework. They are about words spelling, grammar, sentence patterns, structure, thinking style, and similar concerns. Thus, it is very difficult for teachers to grade the students writing homework. Teachers should point out all the mistakes on the writing composition. It will consume much time and energy. That leads to some teachers seldom assign students the writing composition assignments. If so, the students' problems are also problems. How to deal with such difficulty? Teachers can divide their students into groups. They can ask the students to grade the composition first. And they also can just grade part of the groups. Make sure each group is graded in different time. This approach guarantees that students will learn more when grade the other students' work and it can reduce the teachers' work stress. It also can foster the students' sense of responsibility. If students do not hand in their homework, teachers will teach them a lesson by giving the students failure grades. It's understandable for teachers to punish students like this. However it's not the best strategy to solve the problem. The punishment only strengthens the students' sense of failure (Darling-Hammond, Ifill-Lynch, 2006). It's no use for the students' further learning. And no italics will weaken the teacher-student relationship. Punishment is not the basic aim. Students' after class time is limited, if their homework is too much, they cannot spend much more time on the homework. What's more, the quality of the homework will not be good. And at present society, most students undertake much pressure. Such pressure is from their own, their parents, their peers, and the society. After class, they have many things to do. They have to develop their other interests. Some are their own interests and some are from the parents' wishes and even the society. Under such condition, if teachers assign students much homework, the students cannot finish the homework on time let along hand in high quality homework. Some students even want to try some special way to finish their homework. For example, they may make a copy of others' homework. If the students hold such kind attitude on homework, they can learn nothing from the homework. There is a fact that many students are unwilling to finish the homework. They think it as a burden. There are all kinds of reasons. One of the most obvious reasons is that the students do not know how to finish the homework. They don't know how to start the work. They did not comprehend their teachers' demand and instructions on class. They don't know what to do. What's more, the students think the homework is meaningless, because teachers don't give their homework immediate feedback or grade their homework in time. It makes the students feel disappointment.

\section{Conclusion}

Homework ran through students' school life. It bonds teachers, students and even parents. Teachers should pay more attention to the assigning of homework to make full use the function of it.

\section{References}

1. Brock, C. H., Lapp, D., Flood, J., Fisher, D., \& Han, K. T. (2007). Does homework matter? An investigation of teacher perceptions about homework practices for children from non-dominant backgrounds. Urban Education, 42(4), 349-372.

2. Epstein, J. L., \& Van Voorhis, F. L. (2001). More Than Minutes: Teachers' Roles in Designing Homework. Educational Psychologist, 36(3), 181-193.

3. Darling-Hammond, L., \& Ifill-Lynch, O. (2006). If They'd Only Do Their Work! (Cover story). Educational Leadership, 63(5), 8-13.

4. Van Voorhis, F. (2011). Costs and benefits of family involvement in homework. Journal of Advanced Academics, 22(2), 220-249. 